\title{
AS LÍNGUAS DA ITÁLIA ANTIGA: UM BREVE PANORAMA
}

Jasmim Drigo ${ }^{1}$

RESUMO: Este artigo traça um panorama das línguas de maior expressão da Itália Antiga durante os séculos VI a I a.C. As línguas indo-europeias itálicas recebem mais atenção neste estudo por se tratarem de línguas com mais vestígios textuais e por serem mais inteligíveis que as demais, são elas: latim-falisco, úmbrio, osco e piceno meridional. As indo-europeias não itálicas apresentam similaridades com as itálicas, mas ainda assim são menos inteligíveis, são elas: venético e messápico. As línguas não indo-europeias apresentam estruturas fonológicas, morfológicas e sintáticas diferentes e menos vestígios textuais, por isso são mais complicadas de se analisar, são elas: etrusco, rético e piceno setentrional. O objetivo desse panorama é demonstrar a diversidade linguística da região e apresentar bibliografia atualizada e relevante sobre o assunto.

PALAVRAS-CHAVE: Itália Antiga; Latim; Sabélico; Línguas Indo-europeias.

ABSTRACT: This article presents an overview of the main languages of Ancient Italy during the centuries VI to I BC. I focus on Italic Indo-European languages, namely Latin-Faliscan, Umbrian, Oscan and South Picene, because they both have more textual evidence available and are more intelligible than the others. Non-Italic Indo-European languages show similarities with Italic, but they are not so comprehensible. These languages are the Venetic and the Messapic. Non-IndoEuropean languages have different phonological, morphological and syntactic structure, as well as fewer texts, therefore, they are more complex to analyze. These are: Etruscan, Rhetic and North Picene. The aim of this overview is to demonstrate the linguistic diversity of the area and to provide recent and relevant bibliography.

KEYWORDS: Ancient Italy; Latin; Sabellic; Indo-European languages.

\section{Introdução}

Quando se fala em Itália Antiga muito comumente se menciona apenas o latim como língua da região, mas o fato é que existiam diversas línguas e povos coexistindo na península itálica durante os séculos VI a I a.C. Após esse período, o Império Romano se expande de tal maneira que acaba por englobar os povos da região e não se tem mais vestígios escritos das demais línguas. Ainda que não hajam evidências incontestáveis sobre quando as demais línguas italianas

\footnotetext{
${ }^{1}$ Doutoranda em Letras Clássicas na Universidade de São Paulo. E-mail: jasmim.drigo@usp.br
} 
realmente desapareceram, após o século I a.C. não há mais evidências textuais diretas dessas línguas. ${ }^{2}$

Pode-se separar as línguas da Itália Antiga em dois blocos: línguas indoeuropeias e não indo-europeias. Dentre as que podem ser classificadas como indo-europeias, tem-se: latim-falisco, sabélico, venético e messápico. As não indo-europeias de maior expressão são: etrusco, rético e piceno setentrional. Posto isto, é importante ressaltar a diferença entre línguas italianas e itálicas a fim de explicitar a terminologia usada neste artigo. Todas as línguas da península itálica serão aqui chamadas de italianas, porém, apenas as línguas italianas indoeuropeias serão denominadas itálicas. Isto porque elas fazem parte do subgrupo itálico, descendentes do proto-indo-europeu.

Este estudo procura discutir um pouco cada uma dessas línguas, de modo que se possa visualizar o panorama linguístico da região. A descrição será de caráter introdutório, sem pretensões exaustivas, mas é fornecida uma bibliografia de apoio para possíveis aprofundamentos das línguas mencionadas. A lista de línguas existentes na região tampouco é exaustiva. Certas línguas foram omitidas por não terem desempenhado um papel central na história da península ou por precisarem de análises mais completas - como o lepôntico ao norte da península e o grego ao sul, por exemplo -, algo que o espaço aqui não permite.

No mapa abaixo é possível observar onde essas línguas eram faladas durante o século IV a.C.

${ }^{2}$ Cronologia completa das línguas itálicas da época pode ser encontrada em De Vaan, 2008, p. 2). As referências bibliográficas de cada língua apresentada nas seções abaixo também corroboram a ideia de que não se encontra inscrições dessas línguas italianas (além do latim) depois do séc. I a.C. 


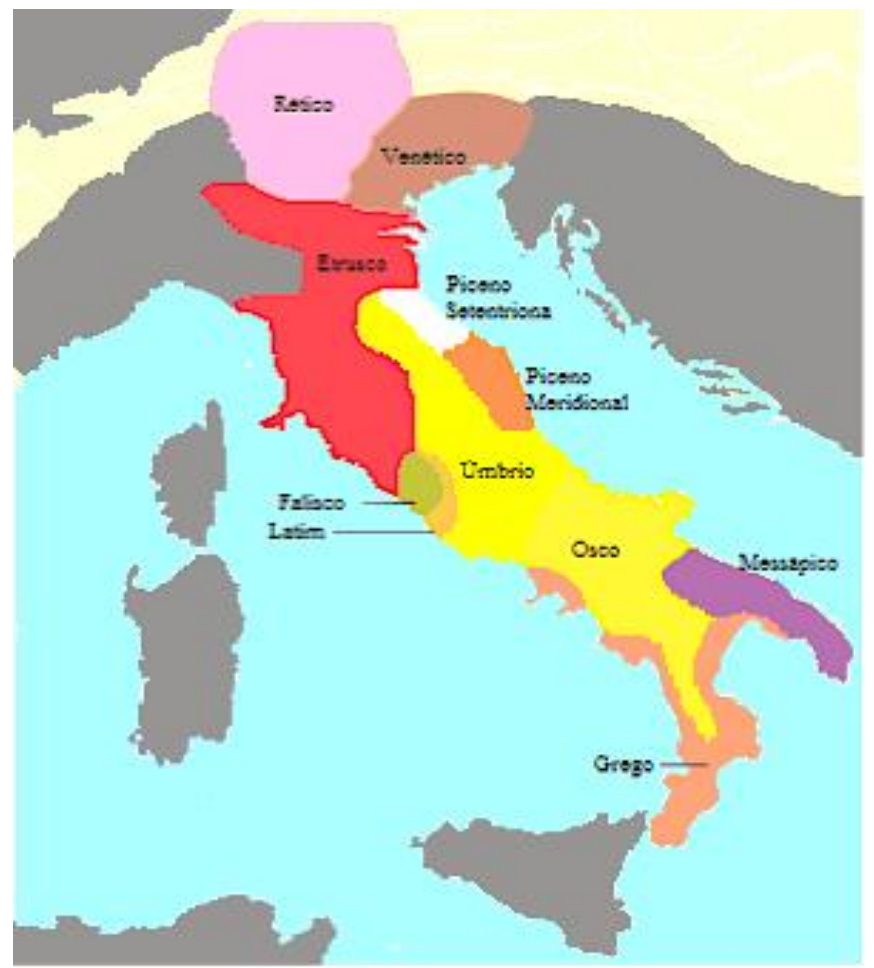

Fig. 1 - Mapa da península itálica no século IV a. C. com as línguas de maior expressão na época (Crédito à autora)

1 Línguas indo-europeias: ramo latim-falisco

\subsection{Latim}

O latim é a língua da Itália antiga que possui mais vestígios textuais e que sobreviveu por mais tempo. Por causa disso, costuma-se fazer recortes temporais para facilitar o manejo com a língua. Ainda que esse recurso seja útil, é importante lembrar que todo recorte é arbitrário e que diferentes estudiosos o fazem de maneiras distintas. Para este artigo, optou-se por adotar a divisão feita por Weiss (2009, p. 23-4):

Latim Muito Arcaico (LMA): séculos VI - III a.C.

Latim Arcaico (LA): séculos III - II a.C.

Latim Clássico (LC): séculos I a.C. - III/IV d.C.

Latim Tardio (LT): séculos III/ IV - VII d.C. 
Esse recorte temporal é interessante porque evidencia as mudanças ocorridas na diacronia da língua. Abaixo, segue uma comparação entre o Latim Muito Arcaico e Latim Clássico para que se possam observar essas diferenças. 1.1.1 Latim Muito Arcaico

Inscrição Duenos Século VI ou V a.C.

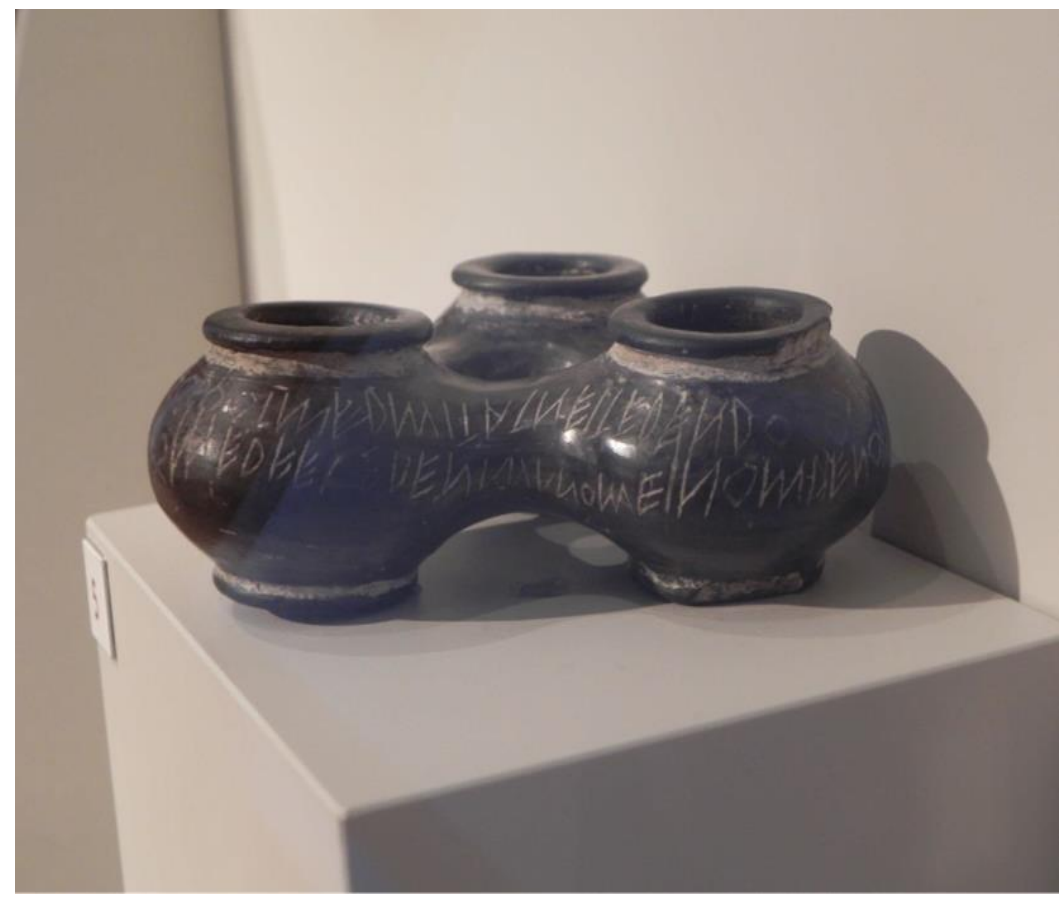

30894,3 Staatliche Museen, Berlim

(Foto tirada pela autora)

Transcrição:

IOVESATDEIVOSQOIMEDMITATNEITEDENDOCOSMISVIRCOSIED

ASTEDNOISIOPETOITESIAIPACARIVOIS

DVENOSMEDFECEDENMANOMEINOMDVENOINEMEDMALOST

ATOD

Interpretação segundo Brent Vine (2012):

IOVESAT() DEIVOS()QOI() MED() MITAT

PRES.,3SG. NOM.,SG. ACS.,SG. PRES.,3SG.

iurat deos qui me 'mittit'

"Aquele que me 'envia'(?) jura pelos deuses" 
NEI() TED()

PART. ACS .,SG.

ENDO()COSMIS()VIRCO()SIED

ni in te [= erga te] comis virgo sit

"se a jovem não for amável contigo,"

\section{ASTEDNOISIOPETOITESIAIPACARIVOIS}

?

DVENOS() MED() FECED() EN() MANOMEINOM() DVENOI

NOM.,SG. ACS.,SG. PERF.,3SG. PREP. ? DAT.,SG.

bonus me fecit in MANOMEINOM bono

"um bom homem me fez em MANOMEINOM(?) para um bom homem"

NE() MED() MALOS() TATOD ou NE() MED() MALO(S)() STATOD

PART. ACS.,SG. NOM.,SG. PRES.3SG. PART. ACS.,SG. NOM.,SG. PRES.3SG.

ne me malus tollito clepito

"que uma pessoa má não me roube"

Há algumas características desse trecho que podem ser claramente explicadas como frutos de arcaísmo. Por exemplo, a presença de -s- intervocálico (como em IOVESAT) só pode ser encontrada em inscrições do LMA e do LA. Depois disso, ocorreu a rotacização de todo $-s$ - intervocálico: IOVESAT > LC iữat. Outro exemplo é a presença do $-d$ nos pronomes acusativos (MED, TED), os quais perdem essa consoante final no LC: MED > LC $m e$, e TED > LC te.

\subsubsection{Latim Clássico}

O LC é o latim que possui a maior produção de textos, não apenas porque o período foi muito frutífero (Júlio César, Virgílio, Ovídio, Cícero etc.), mas também porque muitos autores posteriores procuraram imitar a língua dessa época. Trata-se de uma língua composta por seis casos: vocativo, nominativo, acusativo, genitivo, dativo e ablativo. Existem cinco declinações para os nomes, sendo que há poucos nomes da quarta e da quinta declinação. Ela conta com quatro conjugações de verbos, além de verbos irregulares (normalmente verbos de alta frequência como sum 'ser; estar'). Um bom exemplo de LC é o início da Guerra Gálica: 
Gallia est omnis diuisa in partestres quarum unam

NOM.,SG. PRES.,3SG. NOM.,SG. PREP. ACS.,PL. GEN.,SG. ACS.,SG. ${ }^{3}$ incolunt Belgae, aliam Aquitani, tertiam, qui ipsorum PRES.,3PL. NOM.,PL. ACS.,SG. NOM.,PL. ACS.,SG. NOM.,PL. GEN.,PL. lingua Celtae, nostra Galli appellantur ABL.SG. NOM.,PL. ABL.,SG. NOM.,PL. PRES.,3PL.

"A Gália é toda dividida em três partes, das quais uma os belgas habitam, outra, os aquitânios, e a terceira, aqueles que na sua própria língua se chamam celtas, [mas] na nossa de gauleses (...)”. (César, Guerra Gálica, Livro I, 1).4

\subsection{Falisco}

O falisco existiu do século VI ao I a.C. e, assim como as demais línguas e dialetos da península itálica, desapareceu com a expansão do Império Romano por volta do século I a.C. Ainda existe uma polêmica quanto ao estatuto do falisco: seria uma língua parte do subgrupo latim-falisco ou apenas um dialeto do latim? Joseph \& Wallace (1991) defendem que seria uma língua independente, principalmente com base no argumento do desenvolvimento das consoantes aspiradas vozeadas do PIE, que apresentam resultados diferentes entre o latim e o falisco. As consoantes aspiradas vozeadas são o motivo de maior polêmica dentro dessa discussão, mas Bakkum (2009, p. 64-8) argumenta que seria possível um desenvolvimento desse tipo em um mesmo subgrupo, que seria apenas resultado de uma variação dialetal. Bakkum (2009) também analisa evidências sintáticas, morfológicas, lexicais e até culturais para concluir que o falisco é de fato um dialeto do latim. A discussão, porém, continua sem consenso.

- Inscrição Ceres 600 a.C. (Bakkum, 2009, 395-406)

ceres: far[]e[]tom: []ufl]ui[]m: []5

NOM.,SG. ?

adeuios: mama z[e]xtos med flif]iqod:

NOM.,SG. ACS.,SG. PERF.,3PL.

"Que Ceres (?),

3 Ver Apêndice: Siglas e Abreviações.

4 Para mais sobre o latim em geral, ver Leumann, 1933; Meiser, 1998; Baldi 2002; De Vaan, 2008; Weiss 2009.

5 [] representam lacunas na inscrição. 
Mama e (?) Zexto Euio me fizeram.”6

2 Línguas indo-europeias: ramo sabélico

\subsection{Piceno meridional}

Há 23 inscrições em pedra ou bronze datadas do século VI ao IV a.C. A língua possui um alfabeto próprio, construído com base no alfabeto etrusco meridional. Grande parte do vocabulário do piceno meridional é ainda desconhecido, mas sua estrutura pode ser compreendida com mais facilidade. Assim, é relativamente comum entender em qual caso um nome se encontra, mas não saber exatamente o seu significado (muitos nomes próprios entram nessa categoria).

- Inscrição funerária Sp MC 1 (Rix, 2002):

apaes: qupat: e]smín: púpúniș: nír: mefiín: veiat:

NOM.,SG. PRES.,3SG. LOC.,SG. ? NOM.,SG. LOC.,SG. SUBJ.,3SG.

vepetí

LOC.,SG.

"Ape jaz neste lugar púpúnis, o homem veiat no meio da tumba”7

\section{2 Úmbrio}

Os vestígios da língua datam do século VI a I a.C. Dentre as línguas sabélicas, é a que possui o maior número de vestígios escritos, cerca de 30 inscrições. Uma dessas inscrições são as Tábuas Iguvinas (texto do século III a.C.), tábuas que compõem o maior texto itálico não latino: 7 tabletes de bronze que descrevem um ritual religioso.

- Tábuas Iguvinas Ia, 1-3 (Rix 2002, 47):

este : persklum : aves : anzeriates : enetu :

ACS.,SG. ABL.,SG. IMP.,3SG

"Começa esta cerimônia com a observação das aves,"

pernaies : pusnaes : preveres : treplanes :

ABL.,SG. ABL.,SG. ABL.,SG.

${ }^{6}$ Para mais sobre o falisco, ver Joseph \& Wallace, 1991 e Bakkum, 2009.

7 Para mais sobre o piceno meridional, ver Marinetti, 1985. 
"as que estão na frente e as que estão atrás; na frente do portão Trebulano"

iuve : krapuvi : tre buf : fetu : arvia : ustentu :

DAT.,SG. ACS.,SG. IMP. ACS.,SG. IMP.,3SG.

"sacrifica três bois a Júpiter Grabóvio; oferece grãos"8

\subsection{Osco}

Língua com vestígios do século VI a I a.C., com cerca de 400 pequenas inscrições, mas praticamente todas muito curtas. Em termos linguísticos, podese dizer que o osco é a língua sabélica mais conservadora dentre as línguas itálicas. Um bom exemplo desse conservadorismo é o fato de não haver monotongação, isto é, o osco não simplifica ditongos, processo que sempre ocorre em úmbrio, e que acontece às vezes em latim: tal como em osc. kvaísstur $v s$ umb. kvestur (cf. lat. quaestor “tipo de magistrado”).

- Cippus Abelanus 6-10 (Rix 2002, 114 / Crawford 2011, 887-92)

\section{lígatúís. Abell[anúís}

DAT.,PL.

\section{íním. lígatúís. Núvlanúís}

CONJ. DAT.,PL.

pús. senateís. tanginúd

NOM. GEN.,SG. ABL.,SG.

suveís. pútúrúspíd. lígatú[s]

GEN.,SG. NOM.,SG.

\section{fufans.}

IMPF.,3SG

“(...) para os embaixadores abelanos e para os embaixadores nolanos, por decreto do próprio senado, cada embaixador era (...)"9

\section{Língua indo-europeia: venético}

Também possui vestígios que datam do século VI ao I a.C., com mais de 400 inscrições, mas quase todas são muito curtas ou formulares. É uma língua indo-europeia, mas ainda não há consenso se se trata de uma língua itálica ou não.

\footnotetext{
${ }^{8}$ Para mais sobre o úmbrio, ver Devoto, 1937; Poultney, 1959; Meiser, 1986; Weiss, 2010.

9 Para mais sobre o osco, ver McDonald, 2015 e Zair, 2016. Para mais sobre línguas sabélicas em geral, ver Buck, 1904; Rix, 2002; Crawford et al., 2011.
} 
Os alfabetos venéticos são derivados dos alfabetos etruscos setentrionais, mas com a adição da letra $\{0\}$ do grego (Lejeune, 1974, p. 21). Foi incorporado também um sistema de pontuação emprestado do etrusco, no qual apenas sequências CV ou V são permitidas: .CV. / .V. / CV.C.

- Lejeune 57 (1974, p. 214-5), PP Es 2 (Necrópolis de Capodaglio)

.e.go vhu.k.s.siia.i.

NOM.,SG. DAT.,SG.

\section{vo.l.tiio.m.mni}

na.i.

DAT.,SG.

"Eu (sou) para Fuksia Voltioma”10

\section{Língua indo-europeia: messápico}

Língua com registro durante os séculos VI ao I a.C., com cerca de 600 inscrições curtas de Apuliae Salento. É possível classificá-la como indo-europeia, mas não se enquadra em nenhum subgrupo itálico.

O messápico era escrito em duas variantes de alfabeto baseado no grego (emprestado da colônia dórica de Tarento): o messápico e o apúlio.

- Inscrição de Vaste 1-2 (Haas, 1962, p. 91)

klohi zis $\quad$ Ootori Amartapido Vasteibas ta

IMP.,2SG. VOC. ? ABL.,SG. NOM.,SG.

'Ouve, ó Zeus, esse baustaniano de Amartapido,

veina vvaran in daranӨoa Vasti staboos

NOM.,SG. ACS.,SG. PREP. ABL.,SG. GEN.,SG. IMPF.,3SG.

"a lei dos baustanianos estabeleceu no senado esse assunto"11

10 Para mais sobre o venético, ver Lejeune, 1974.

${ }^{11}$ Para mais sobre o messápico, ver Haas, 1962. 
5 Línguas não indo-europeias: ramo tirsênico

\subsection{Etrusco}

Possui vestígios durante os séculos VII - I a.C., com cerca de $12 \mathrm{mil}$ inscrições. Não há resquício de literatura, ainda que as fontes indiretas de autores gregos e romanos acusem a existência de literatura etrusca. Apresenta vocabulário pequeno e especializado, com cerca de 700 itens lexicais diferentes. Possui também características linguísticas peculiares, como por exemplo: processos morfológicos aglutinativos; alguns casos são formados a partir do caso pertinentivo; não há consoantes oclusivas sonoras; entre outros. Essas características peculiares, tão diferente das demais línguas itálicas, é que servem como evidência para classificar o etrusco como língua não indo-europeia.

Liber Linteus Zagrebiensis é o único texto etrusco que sobreviveu sem ser uma inscrição. Trata-se de um calendário com datas de festivais religiosos datado do século II a.C. Esse texto foi encontrado no Egito, no verso de uma bandagem que estava sendo utilizada para envolver uma múmia (Weiss, 2016, p. 11).

- Incrição de Volsinii: ETP 214 - 600-500 a.C. (Wallace, 2008, p. 137)

\section{mi aveles metienas}

NOM., 1SG 2GEN. SG., 1GEN., SG.

"Eu sou (a tumba) de Avele Metiena"12

\subsection{Rético}

Segundo Rix (1998, 2008), é possível identificar mais duas línguas da mesma família que o etrusco: o lêmnio (localizado no nordeste do mar Egeu) e o rético. Conseguir identificar línguas parentes, isto é, línguas que possuem um ancestral em comum e inovações semelhantes, é essencial para a compreensão e análise de línguas pouco conhecidas. No entanto, o rético e o lêmnio possuem ainda menos vestígios do que o etrusco, o que dificulta o entendimento de todo o ramo tirsênico. Há cerca de 100 inscrições réticas, mas todas são muito curtas e muitas vezes ininteligíveis.

\footnotetext{
${ }_{12}$ Para mais sobre o etrusco, ver Rix, 2004 e Wallace, 2008.
} 
- MA-9 (Schumacher, 1992, p. 163)

pi $\square$ ale lemais zinake

NOM.,SG. GEN.,SG. PASSADO,3SG.

"Pitale de Lemai me consagrou" ou "Pitale, [filho de] Lemai, me consagrou" (?)13

\section{Língua não indo-europeia: piceno setentrional}

Língua com quatro inscrições, que datam dos séculos VII a VI a.C. Muito pouco se conhece sobre o piceno sententrional, pois há escassas evidências e se trata de uma língua não indo-europeia, o que causa mais dificuldade na sua compreensão. ${ }^{14}$

- Stele di Novilara 1-2 (di Carlo, 2005-6, p. 6):

mimniś . erút . gaareśtadeś

rotnem . úvlin . parten úśs ${ }^{15}$

\section{Conclusão}

Este artigo possui caráter didático e tem como objetivo apresentar um panorama das principais línguas da Itália Antiga, para que sirva de ponto de partida para pesquisas mais aprofundadas. Ainda que a discussão linguística de línguas italianas antigas (além do latim) seja incipiente no Brasil, ${ }^{16}$ essas línguas estão em alta na pesquisa indo-europeia internacional, com novos artigos e livros sendo publicados e novas inscrições sendo encontradas a todo momento. Do ponto de vista histórico, entender um pouco sobre a diversidade linguística também pode auxiliar na compreensão da pluralidade cultural da região.

\footnotetext{
13 Para mais sobre o rético, ver Schumacher, 1992 e Rix, 1998.

14 Para mais sobre o piceno setentrional, ver Agostiniani, 2003 e di Carlo, 2005-6.

15 Tradução desconhecida.

${ }^{16}$ Exemplos de produção recente sobre o assunto no Brasil como Drigo, 2016 são escassos.
} 


\section{REFERÊNCIAS BIBLIOGRÁFICAS}

\section{Fontes Primárias}

Crawford, M. H. et al. (ed.) Imagines Italicae: A Corpus of Italic Inscriptions. London: Institute of Classical Studies, University of London, 2011, vols. I-III.

Devoto, Iacobo. Tabulae Iguvinae. Roma: Typis Publicae Officinae Polygraphicae, 1937.

Marinetti, Anna. Le Iscrizioni Sudpicene: I Testi. Firenze: Leo S. Olschki Editore, 1985 .

Poultney, James. The Bronze Tables of Iguvium. Baltimore: American Philological Association, 1959.

Rix, Helmut. Sabellische Texte: die Texte des Oskischen, Umbrischen und Südpikenischen. Heidelberg: Universitätsverlad C. Winter, 2002.

Schumacher, Stefan. Die rätischen Inschriften: Geschichte und heutiger Stand der Forschung. Innsbruck: Institut für Sprachwissenschaft der Universität Innsbruck, 1992.

\section{Bibliografia Crítica}

Agostiniani, Luciano. Le iscrizioni di Novilara. In: I Piceni e l'Italia MedioAdriatica. Atti del XXII Convegno di Studi Etruschi ed Italici. Ascoli Piceno, Teramo, Ancona, 9-13 aprile 2000. Pisa \& Roma: Istituti Editoriali e Poligrafici Internazionali, 2003, p. 115-125.

Bakkum, Gabriel. The Latin Dialect of the Ager Faliscus. Amsterdam: University of Amsterdam, 2009, vols. I e II.

Baldi, Philip. The Foundations of Latin. Berlim: De Gruyter, 2002.

Buck, Carl. A Grammar of Oscan and Umbrian. Boston: Athenaeum Press, 1904.

de Vaan, Michiel. Etymological Dictionary of Latin and the other Italic Languages. Leiden \& Boston: Brill, 2008.

di Carlo, Pierpaolo. L'Enigma Nord-piceno: Saggio Sulla Lingua Delle Stele Di Novilara E Sul Loro Constesto Cultural. Quaderni del dipartimento di linguistica, studi 7. Firenze: Università degli studi di Firenze, 2005-6.

Drigo, Jasmim. Síncope Vocálica na Itália Antiga. Dissertação de Mestrado, Letras Clássicas, DLCV/FFLCH, Universidade de São Paulo, 2016.

Haas, Otto. Messapische Studien. Heideelberg: Winter, 1962.

Joseph, Brian; Wallace, Rex. Is Faliscan a local Latin Patois? Diachronica, 8, 2, 1991, p. 159-186.

Lejeune, Michel. Manuel de la Langue Vénète. Heidelberg: Winter, 1974.

Leumann, Manu. Lateinische Laut- und Formenlehre 1933. Munique: Beck, 1933 .

McDonald, Katherine. Oscan in Southern Sicily: Evaluating Language Contact in a Fragmentary Corpus. Cambridge: Cambridge University Press, 2015. 
Meiser, Gerhard. Lautgeschichte der umbrischen Sprache. Innsbruck: Institut für Sprachwissenschaft der Universität Innsbruck, 1986.

Historische Laut- und Formenlehre der lateinischen Sprache. Darmstadt: Wissenverbindet, 1998.

Rix, Helmut. Rätisch und Etruskisch. Innsbruck: Institut für Sprachwissenschaft der Universität Innsbruck, 1998.

Etruscan. In: Woodard, R. (ed.) The Ancient Languages of the World. Cambridge: Cambridge University Press, 2004, p. 141-164.

Vine, Brent. A Note on the Duenos Inscription. Los Angeles, 1999. Republicado em Ivanov, E.; vine, B. (eds). UCLA Indo-European Studies 1, 2012.

Wallace, Rex.Zikh Rasna: A Manual of the Etruscan Language and Inscriptions. Nova York: Beech Stave Press, 2008.

Weiss, Michael. Outline of the Historical and Comparative Grammar of Latin. New York/Ann Arbor: Beech Stave Press, 2009.

. Language and Ritual in Sabellic Italy. Leiden/Boston: Brill, 2010.

. Etruscan. Handout to Leiden Summer School of Linguistics 2016.

Leiden, 2016.

Zair, Nicholas. Oscan in the Greek Alphabet. Cambridge: Cambridge University Press, 2016.

Apêndice: Siglas e Abreviações

$\begin{array}{ll}\text { ABL. } & \text { ablativo } \\ \text { ACS. } & \text { acusativo } \\ \text { C } & \text { consoante } \\ \text { DAT. } & \text { dativo } \\ \text { GEN. } & \text { genitivo } \\ \text { IMPF. } & \text { verbo no imperfeito } \\ \text { IMP. } & \text { verbo no imperativo } \\ \text { LA } & \text { latim arcaico } \\ \text { LC } & \text { latim clássico } \\ \text { LMA } & \text { latim muito arcaico } \\ \text { LOC. } & \text { locativo } \\ \text { NOM. } & \text { nominativo } \\ \text { PART. } & \text { partícula } \\ \text { PIE } & \text { Proto-Indo-Europeu } \\ \text { PL } & \text { plural }\end{array}$


Mare Nostrum, ano 2017, n. 9

PRES. verbo no presente do indicativo

SG. singular

SUBJ. verbo no subjuntivo

$\mathrm{V} \quad$ vogal

VOC. vocativo 